\title{
Mathematikal model of calclation parabola-cylindirical solar hot water systems of industrial enterprises
}

\author{
SULAYMONOV HUSANBOY MANNOPOVICH \\ Ferghana Polytechnic Institute. \\ ERGASHEV SIROJIDDIN FAYAZOVICH . \\ Ferghana Polytechnic Institute. \\ MAMADIEVA DILXUMOR TOLIBJONOVNA \\ Ferghana Polytechnic Institute.
}

\begin{abstract}
The article analyzes a mathematical model for calculating solar parabola cylindrical hot water systems for industrial and municipal enterprises. The formulas for determining heat losses associated with radiant and convective heat exchange, as well as useful heat energy and efficiency of solar parabolacylindrical systems for obtaining heat for industrial purposes are given.
\end{abstract}

Keywords: Solar radiation, energy, temperature, heat supply, process steam, productivity, battery, hot water, thermal energy, electricity, optical losses, heat losses, hot water supply, energy balance, industry

\section{INTRODUCTION}

Most solar parabola-cylindrical hot water systems for industrial and municipal enterprises operate according to the thermal model shown in Fig.1 and consist of the following main components: parabola-cylindrical collectors, accumulator tank, circulation pumps and hot water supply doubler 1, 2, 4, 5, 6. The system is provided with hot water with a temperature of $60 \div 100^{\circ} \mathrm{C}$.

The hot water supply system is made according to a single-circuit scheme, i.e. the heated water in parabola-cylindrical collectors enters the hot water storage tank. Water from the Central water supply network enters the lower part of the battery tank, and hot water for technological processes are taken from the upper part of the tank. The system is protected from freezing by draining water from the collectors.

\section{MAIN PART}

When the water temperature falls below the required operating temperature for the technological process, $T_{2}^{m}$ the DT doubler is turned on; this will warm up the water coming from the storage tank.

The system works as follows. Circulation of water through parabola-cylindrical collectors occurs if the equilibrium temperature $T_{\infty}$ the absorbing surface of the heat receiver is higher than the temperature $T_{B}$ at the bottom of the battery tank by the amount of $\Delta T$ due to the temperature difference in the main pipelines of this circuit 

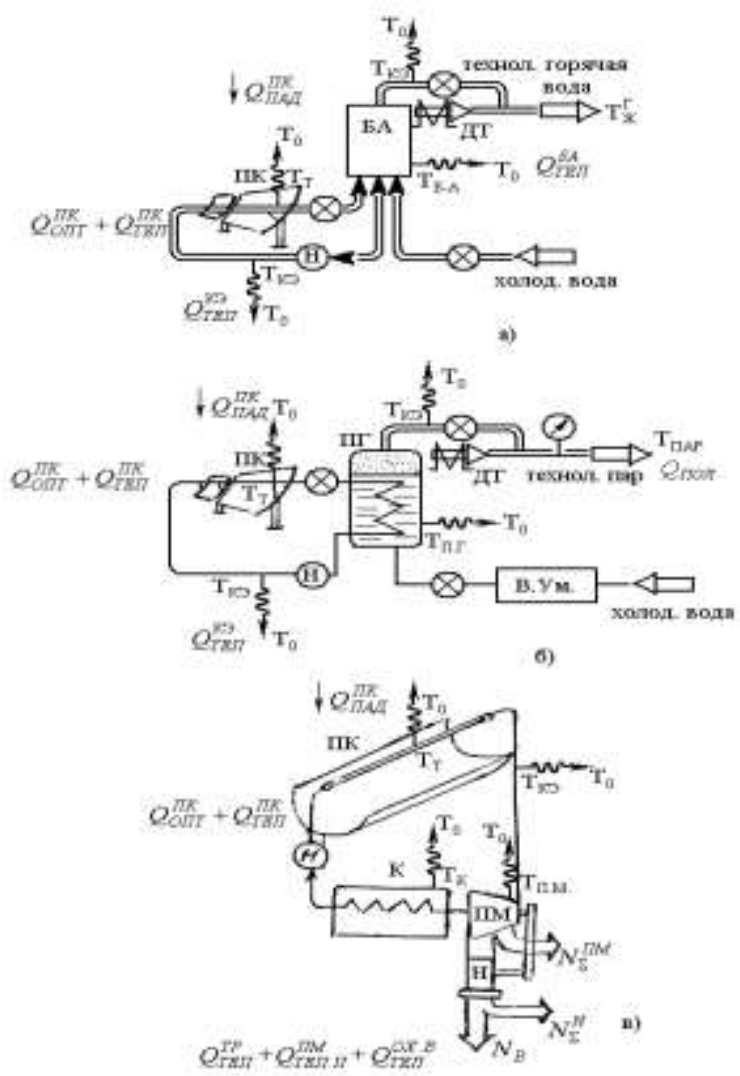

Fig. 1 Thermal models of parabola-cylindrical installations for the production of hot water (a), steam (b) and water lifting (C).

(1) Hot water is extracted from the upper part of the battery tank by the flow rate $m_{r}$ to places where water is collected. From Fig.2 it can be seen that the consumption $m_{r}$ defined as follows:

$m_{r}=m_{\Gamma}^{T}{ }_{n p u} T_{5} \leq T_{\Gamma}^{T}$

and from the equality $m_{r} \cdot C_{P} \cdot T_{E}+\left(m_{\Gamma}^{T}-m_{r}\right) C_{P} \cdot \tau_{x . \text {. }}=m_{\Gamma}^{T} \cdot C_{P} \cdot T_{\Gamma}^{T}$

determine

$$
m_{r}=m_{r}^{T} \frac{\left(T_{\Gamma}^{T}-T_{x .8}\right)}{\left(T_{Б}-T_{x .8}\right)} \quad T_{\bar{L}}>T_{\Gamma}^{T}
$$

where: $T_{\Gamma}^{T}, m_{r}^{T}$-water temperature and flow rate determined by the process load schedule;

$T_{x .8} \quad$ - the temperature of the feed water provided from a Central water supply network. In the description of the mathematical model parabola-cylindrical hot

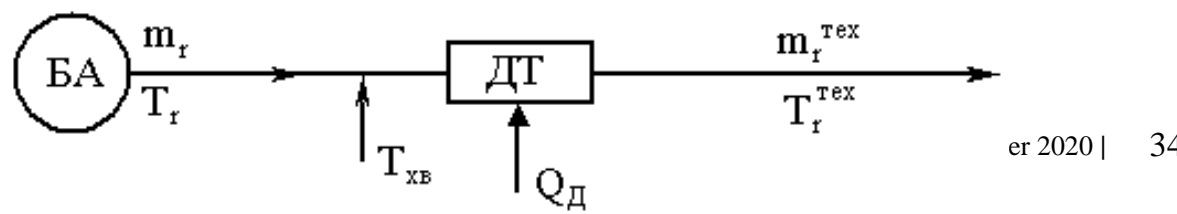

Fig. 2. Scheme for determining $m_{r}$ 
the following assumptions were made: neglect the uneven distribution of solar energy flow between collectors; do not take into account heat loss from the surface of connecting pipelines; based on the results of preliminary calculations, neglect the temperature gradient along the perimeter and heat loss by thermal conductivity to the supporting elements of the heat receiver design. These assumptions make it possible to significantly simplify the mathematical model of the system, and consider parabolocylindric collectors as a single collector.

To consider the energy balance over time, the estimated period of operation of the system is divided into $N$ equal parts in increments $\Delta \tau$, for each $\tau_{i}$ point in time $(i=1,2, \ldots N)$ at the beginning of the step, the thermal balance of each system element is considered. In this case, the main dependencies used for calculating each component of the system at a time $\tau_{i}$ and the functional relationship between the elements are shown below.

Unit parabola-cylindrical collectors. To determine the useful heat $Q_{n \circ \pi}^{n \kappa}$, the collector energy balance equation is used for the energy received from the parabolocylindric collectors in the storage tank, expressed in terms of the equilibrium temperature of the absorbing surface of the receiver $T_{\infty}$ and temperature $T_{5}$ at the bottom of the tank

$Q_{\text {пол }}^{\text {пк }}=F_{3} \cdot F_{R} \cdot U_{L} \cdot C^{-1}\left(T_{\infty}-T_{Б}\right)$

Equilibrium temperature $T_{\infty}$ the absorption surface of the receiver is determined by the formula [7]

$T_{\infty}=T_{O}+\frac{E_{O} \cdot \eta_{O} \cdot K_{3 a n} \cdot C}{U_{L}}$,

where: $K_{3 a n}$-coefficient that takes into account dust on the mirror surface of the hub.

When calculating the flow density of direct solar radiation, the main methods used are the orientation of collectors rotating around a horizontal North-South or East-West axis.

Heat losses associated with partial boiling and evaporation of water are determined by the formula [7]

$Q_{\text {uсn }}^{\text {nот. }}=Q_{\text {пол }}^{\text {пк }}-m_{\kappa} \cdot C_{P}\left(T_{u}-T_{Б}\right)$

where: $T_{u \text { - boiling point of water; }}$

$$
m_{\kappa} \text { - water consumption in the system circuit. }
$$

The flow rate of evaporated water is determined by a well-known formula [8]:

$$
m_{u}=Q_{u} / r
$$

Taking into account (7) the water temperature at the outlet of the heat receiver is determined by the formula:

$$
T_{\kappa}^{\text {выx }}=T_{Б}+\frac{\left(\text { Qnno }-Q_{u c n}^{\text {nom }}\right)}{m_{\kappa} C_{P}}
$$

At the end time of the estimated period of operation of the system, the following values are determined that characterize the balance of water heating energy in parabola-cylindrical collectors:

1. The Sum of the incident (direct component) of solar radiation $\left(Q_{n a d}\right)_{\Sigma}$ on the collector surface perpendicular to the rays:

$$
\left(Q_{n a \partial}\right)_{\Sigma}=\sum_{I=1}^{N}\left(E_{o i} \cdot F_{3} \cdot \Delta \tau \cdot 10^{-3}\right) \text {. }
$$

2. Total solar energy $\left(Q_{\text {noz }}\right)_{\sum}$ absorbed in the collector's heat sink:

$$
\left(Q_{\text {noz }}\right)_{\Sigma}=\sum_{I=1}^{N}\left(E_{o i} \cdot F_{3} \cdot \eta_{o} \cdot \Delta \tau \cdot 10^{-3}\right)
$$


3. The total optical loss in parabola-cilindrical collectors

$\left(Q_{\text {onm }}^{\text {nom }}\right)_{\Sigma}=\left(Q_{\text {nad }}\right)_{\Sigma}-\left(Q_{\text {noг }}\right)_{\Sigma}$.

4. Solar energy $\left(Q_{\text {noz }}\right)_{\text {u.h }}$ water absorbed during the operation of the circulation pump through the collector. Value $\left(Q_{\text {noг }}\right)_{u . h}$ defined using equation (11) when the condition is met $T_{\infty} \geq T_{E}+\Delta T$. 5. Total amount of heat $\left(Q_{n \text { пл }}^{n \kappa}\right)_{\Sigma}^{5}$ coming into the storage tank of parabola-cilindrical collectors $\left(Q_{\text {пол }}^{\text {пк }}\right)_{\Sigma}^{5}=\sum_{i=1}^{N} Q_{\text {пол }}^{\text {пк }} \Delta \tau \cdot 10^{-3}=\sum_{i=1}^{N}\left[\left(m_{k}-m_{u}\right) C_{P}\left(T_{\kappa}^{\text {вых }}-T_{\text {Б }}\right) \cdot \Delta \tau \cdot 10^{-3}\right]$ 6. Heat losses in the collector heat sink $\left(Q_{m e n}^{\text {nom }}\right)_{\text {нв }}^{m . c}$ caused by the impossibility of
heat carrier of the absorbed solar radiation under the condition $T_{\infty}<T_{B}+\Delta T$ $\left(Q_{\text {mеn }}^{\text {nom }}\right)_{\text {нв }}^{\text {mс }}=\left(Q_{\text {nог }}\right)_{\Sigma}-\left(Q_{\text {nог }}\right)_{\Sigma}-\left(Q_{\text {nог }}\right)_{\text {u. } . н}$

7. The total heat loss $\left(Q_{\text {men }}^{\text {nom }}\right)_{\Sigma}$ taking into account heat loss $\left(Q_{m e n}^{\text {nom }}\right)_{u}$ partially evaporated water at the rate of $m u$

$$
\left(Q_{\text {men }}^{\text {nom }}\right)_{\Sigma}=\sum_{i=1}^{N}\left[\left(m_{u i} \cdot C_{P}\right)\left(T_{u}-T_{Б}\right)+\left(Q_{m e n}^{\text {nom }}\right)_{\text {нв. }}^{m . c}\right] \Delta \tau \cdot 10^{-3}
$$

8. Heat losses in the collector during operation of the pump:

$$
\left(Q_{\text {men }}^{\text {nom.u }}\right)_{u}=\left(Q_{\text {пог }}\right)_{u . \mu}-\left(Q_{\text {пол }}^{\text {nк }}\right)_{\Sigma}^{5}-\left(Q_{\text {men }}^{\text {nom }}\right)_{\Sigma}
$$

The tank is a heat accumulator. To simplify the mathematical model of the heat storage tank, we write down the heat balance equation without taking into account stratification and heat loss from the tank surface [7, 8, 9].:

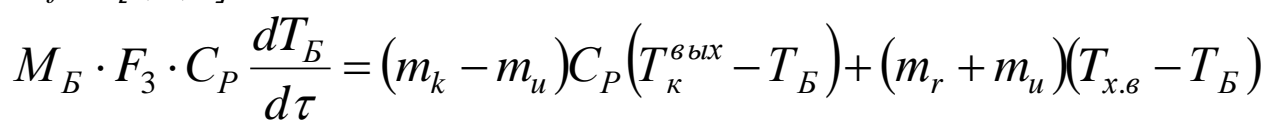

where: $M_{5}$ - mass of water in the accumulator tank per $1 \mathrm{~m} 2$ of the aperture area of the parabolacylindrical collector, $\mathrm{kg} / \mathrm{m} 2$

Integrating equation (23) according to the Euler model, we determine the temperatures $T_{\text {Ei+1 }}$ water at the end of the time step:

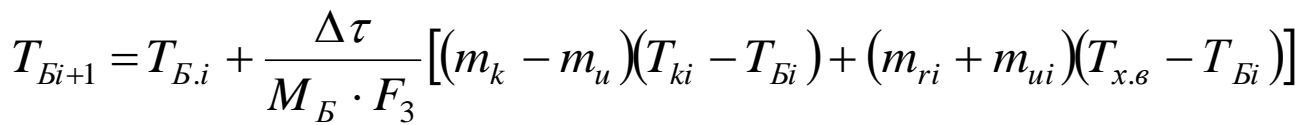

Backup hot water supply. Total amount of energy $\left(Q_{Д}\right)_{\Sigma}$ the water consumed for preheating by the backup in the load loop to the temperature $T_{\Gamma}^{T}$ during the estimated period of operation of the system, it is determined by the formula:

$$
\left(Q_{д}\right)_{\Sigma}=\sum_{i=1}^{N}\left[m_{\Gamma i}^{T} \cdot C_{P}\left(T_{\Gamma}^{T}-T_{Б i}\right) \cdot \Delta \tau \cdot 10^{-3}\right]
$$

Hot water supply load loop. Total amount of energy $\left(Q_{H}\right)_{\sum}$ the load that is diverted to the consumer with the water flow rate is determined by the following equation: 
$\left(Q_{H}\right)_{\Sigma}=\sum_{i=1}^{N}\left[m_{\Gamma}^{T} \cdot C_{P} \cdot \Delta \tau\left(T_{\Gamma}^{T}-T_{x . \beta}\right) \cdot 10^{-3}\right]=\left(Q_{H}\right)_{c y m} \cdot N_{\text {э }}$

where: $\left(Q_{H}\right)_{\text {cym }}$ - daily heat load of hot water supply, $k W h /$ day;

$N_{\ni}$ - the number of days of operation of the system during the period of operation, day/year

In addition, at the end time, the total amount of solar heat received by the load from the system and provided by the use of solar energy is determined.

$\left(Q_{c}\right)_{\Sigma}=\sum_{i=1}^{N}\left[m_{r} \cdot C_{P}\left(T_{B}-T_{x .6}\right) \Delta \tau \cdot 10^{-3}\right]$

\section{CONCLUSION}

Thus, according to the above formulas, the energy indicators of solar parabola-cylindrical hot water systems of industrial and municipal enterprises can be determined

\section{REFERENCES}

* Ababa, C. (2013). Factors influencing sustainability of rural community water projects in Kenya (1st ed.). Nairobi: University of Nairobi.

\# Adhiambo, L. (2012). Factors Affecting the Effectiveness of Donner Funded Projects in Akerland. Journal Of Community Psychology, 6(28), 353-362.

\# Armitage, J. (2003). The Institutional Origins of Dynamic Capabilities in Multinational Enterprises, Industrial and Corporate Change.

\# Batti, R. (2014). Challenges Facing Local NGOs in Resource Mobilization. Humanities and Social Sciences, 2 (3), 57 - 64.

* Bollinger, A. and Smith, R. (2001). Managing organizational knowledge as a strategic asset. Journal of Knowledge Management, 5(1), pp. 8-18. https://doi.org/10.1108/13673270110384365

* Chappel(2005).Art and Wellbeing.Sydney, Austrlia: Australia council of arts.

* Cohen, W.M., Nelson, R.R. and Walsh, J.P. (2002). Links and Impacts: The Influence of Public Research on Industrial R\&D. Management Science, 48(1), pp. 1-23.

\# Cochran, W. G. (1963). Sampling Techniques, 2nd Ed., New York: John Wiley and Sons, Inc.

* Crosby, P. B. (1989) Let's talk quality. New York: McGraw-Hill.

* Cyert, R.M. (1991). Knowledge and Economic Development. Operations Research, 39(1), pp. 5-8. https://doi.org/10.1287/opre.39.1.5

* Dill, D. and \& Vught, F. (2010) National Innovation and the Academic Research Enterprise. Baltimore, MD: John Hopkins University Press. 
* Etzkowitz, H. (2003). Innovation in Innovation: The Triple Helix of University-IndustryGovernment Relations. The Social Science Information, 42(3), pp. 293-337. https://doi.org/10.1177/05390184030423002

* Gimenez-Espin JA, Jiménez-Jiménez D, Martínez-Costa M (2013). Organizational culture for total quality management. Total Quality Management\& Business Excellence;24(5-6):678-692.

\# Githinji, C. (2013). Factors affecting sustainability of community based projects in Kitui County, Kenya. Nairobi: Kenyatta University.

\# Lee, Y., (2011). University-Industry Collaboration on Technology Transfer: Views from the Ivory Tower. Policy Study Journal, 26, 69-84.

* Mavoko, M. (2013). Resource mobilization for NGOs in the developing. London: Adonis and Abbet Publishers Limited

* Muijs, D. (2010). Doing quantitative research in education with SPSS. Sage. multidimensional organization culture and performance”, International Journal of Operation \& Production Management, Vol. 31, No. 7, pp. 712-735.

* Mulwa, F. (2010). Demystifying Participatory Community Development (Revised edition). Nairobi.: Pauline's Publications Africa.

* Prajogo, D.I. and McDermott, C.M. (2011), "The relationship between

\$ Psychometrical, vol.16, no. 3, pp. 297-334.

* Saunders, M., Lewis, P., \& Thornhill, A. (2009) Research Methods for Business Students (5th. ed., pp. 318-359). Harlow: Pearson Education.

* Scot, S. (2004). Variation in Spinoff Activities Across Institutions. In Academic Entrepreneurship: University Spinoffs and Wealth Creation. Edward Elgar Publishing.

\# Smith, K. M., Machalaba, C. C., Seifman, R., Feferholtz, Y., \& Karesh, W. B. (2019). Infectious disease and economics: The case for considering multi-sectoral impacts. One Health, 7, 100080.

* World Health Organization [WHO] (2020b). Coronavirus disease 2019 (COVID-19) Situation Report - 46. https://www.who.int/docs/default-source/coronaviruse/situationreports/20200306sitrep-46-covid 19.pdf?sfursn=96b04adf_2

* Zu, X., Robbins, T. L., \& Fredendall, L. D. (2010). Mapping the critical links between organizational culture and TQM/Six Sigma practices. International Journal of Production 